\title{
A New Simplified Model for Predicting of Water Content Effects on Thermal Conductivity of Hygroscopic Materials Buildings
}

\author{
André Talla \\ Department of Industrial and Mechanical Engineering, National Advanced School of Engineering, Yaounde, Cameroon \\ Email address: \\ andre_talla@yahoo.fr \\ To cite this article: \\ André Talla. A New Simplified Model for Predicting of Water Content Effects on Thermal Conductivity of Hygroscopic Materials Buildings. \\ American Journal of Applied Scientific Research. Vol. 2, No. 6, 2016, pp. 48-54. doi: 10.11648/j.ajasr.20160206.13 \\ Received: September 12, 2016; Accepted: October 28, 2016; Published: November 25, 2016

\begin{abstract}
The aim of this paper was to predict the thermal conductivity of local composite materials, particularly used as building materials in Sub-Saharan countries, as a function of their water content. In this work, a new simplified model, based on a physical approach with assumption of an ideal shrinkage of the material during the evaporation of water, was built. Two composite materials were successfully tested providing good fitting and prediction results. Calculated and experimental values of thermal conductivity were in good agreement, with a maximum standard error of $0.037 \mathrm{Wm}^{-1} \mathrm{~K}^{-1}$ for the three hygroscopic materials. In spite of its simplicity, this model leads to a more accurate representation than other classical models of the measured variations of the thermal conductivity of hygroscopic materials with the water content.
\end{abstract}

Keywords: Hygroscopic Material, Water Content, Simplified Model, Thermal Conductivity, Porosity, Density

\section{Introduction}

The local composite materials were used since the fifties, because of their low cost, initially to bring an economic and social response to the production of a habitat intended for the most stripped populations. Today, these building materials interest as well the poor countries as the industrialized countries. The process is traditionally used in several SubSaharan countries, particularly in Cameroon where compressed soil building blocks or insulating material mixed with a building material were very used as building materials.

Some studies concerning the thermal properties of earthbased materials have already been published. Raghavan and Martin [1] developed a model for the prediction of the conductivity of a random distribution of spheres in a continuum of different materials but the water content is not considered. Bouguerra et al. [2] studied the influence of the water content on the thermal properties of wood cement-clay based composites. Nevertheless, only thermal effusivity was investigated. Adam and Jones [3] studied the thermal properties of stabilized soil building blocks but they did not investigate the influence of the water content. Meukam et al. [4] studied the evolution of the thermal properties of stabilized soil building blocks with pouzzolane or sawdust addition as a function of the water content. Nevertheless, no interpretation of the results based on the structure of the material was presented and no predicting model was proposed. Khedari et al. [5] studied the thermal properties of coconut fiber-based soil-cement blocks and Omubo- Pepple et al. [6] studied cement stabilized lateritic bricks with sea shell addition but the influence of the water content was not investigated in these two studies. The same remark may be done concerning the work of Goodhew and Griffiths [7] concerning unfired clay bricks with straw and wood chippings. Bal et al. [8] studied the evolution of the thermal conductivity of laterite based bricks with millet waste additive as function of water content with interpretation of the results based on the structure of the material. They considered the composite material as solid grains in contact with air and liquid water filling the vacuum volume. Moreover, the grains are considered weakly porous with an internal porosity filled with air and liquid water. The interest of the model suggested by these authors, resides in the fine comprehension of the elementary mechanisms.

Since the local composite materials in particular are used for building and are exposed to very different meteorological 
conditions, it is very important to know how their thermal conductivity vary with the water content. To be able to predict their thermal behaviour in various meteorological conditions, the aim of this study was to develop a simplified model enabling the calculation of the thermal conductivity as a function of the water content $X$ and to valid it experimentally for some local composite materials.

\section{Mathematical Models}

\subsection{Thermal Conductivity Models}

Generally, a homogeneous composite material is composed of a solid phase (d), of water (w) and of air (a). By considering $m$ as mass and $V$ as volume, its composition is defined by the following parameters:

- Dry basis water content:

$$
X=\frac{m_{w}}{m_{d}}
$$

- Global porosity of the material:

$$
\varepsilon=\frac{V_{w}+V_{a}}{V}=\varepsilon_{a}+\varepsilon_{w}
$$

where

$$
\varepsilon_{w}=\frac{V_{w}}{V} ; \varepsilon_{a}=\frac{V_{a}}{V} \text { and } V=V_{d}+V_{w}+V_{a}
$$

According to Wiener [9], the lowest possible value of the thermal conductivity is given by the series model and the highest is given by the parallel one:

- The series model:

$$
\lambda=\frac{1}{\frac{\varepsilon_{d}}{\lambda_{d}}+\frac{\varepsilon_{a}}{\lambda_{a}}+\frac{\varepsilon_{w}}{\lambda_{w}}}
$$

where $\varepsilon=\varepsilon_{a}+\varepsilon_{w}$

- The parallel model:

$$
\lambda=\varepsilon_{d} \lambda_{d}+\varepsilon_{a} \lambda_{a}+\varepsilon_{w} \lambda_{w}
$$

- Hashin and Shtrikman models:

Thereafter, for isotropic mixtures, Hashin and Shtrikman [10] shown that the effective thermal conductivity is independent of pore structure and a refined analysis lead to the Hashin-Shtrikman's bound adapted by Tong et al. [11] to a three phase mixture as:

$$
\begin{aligned}
& \lambda_{\text {min }}=\lambda_{a}+\frac{3 \lambda_{a}\left[\varepsilon_{w} /\left(1+f_{w-a}\right)+\varepsilon_{d} /\left(1+f_{d-a}\right)\right]}{\varepsilon_{a}+\varepsilon_{w} f_{w-a} /\left(1+f_{w-a}\right)+\varepsilon_{d} f_{d-a} /\left(1+f_{d-a}\right)} \\
& \lambda_{\text {max }}=\lambda_{a}+\frac{3 \lambda_{d}\left[\varepsilon_{w} /\left(1+f_{w-d}\right)+\varepsilon_{a} /\left(1+f_{a-d}\right)\right]}{\varepsilon_{d}+\varepsilon_{w} f_{w-d} /\left(1+f_{w-d}\right)+\varepsilon_{a} f_{a-d} /\left(1+f_{a-d}\right)}
\end{aligned}
$$

where

$$
\begin{gathered}
f_{w-a}=\frac{3 \lambda_{a}}{\lambda_{w}-\lambda_{a}} \\
f_{d-a}=\frac{3 \lambda_{a}}{\lambda_{d}-\lambda_{a}} \\
f_{w-d}=\frac{3 \lambda_{d}}{\lambda_{w}-\lambda_{d}}
\end{gathered}
$$

$$
f_{a-d}=\frac{3 \lambda_{d}}{\lambda_{a}-\lambda_{d}}
$$

In the literature, several authors proposed models, as a function of the parallel configuration and of the series configuration, to estimate the effective thermal conductivity of a composite material. Among these authors, we can notice:

- The Beck's model [12]

$$
\lambda=\sqrt{\lambda_{\text {series }} \lambda_{\text {parallel }}}
$$

- The Krischer's model [13]

$$
\lambda=\frac{\lambda_{\text {series }} \lambda_{\text {parallel }}}{A \lambda_{\text {series }}+(1-A) \lambda_{\text {parallel }}}
$$

where $\mathrm{A}$ is a constant depending on material.

- The Woodside and Mesmer's model [14]

$$
\lambda=\lambda_{\text {series }}^{\alpha} \lambda_{\text {parallel }}^{1-\alpha}
$$

But among these models, the model of Ingersoll [15] and that of Bal et al. [8] were the more physical models.

- Ingersoll [15]

This author considered that, water in a parallel arrangement with air is in series with the solid structure:

$$
\lambda=\left(\frac{1-\alpha}{\lambda_{d}}+F \frac{\alpha}{\lambda_{a, w}}\right)
$$

$\lambda_{a, w}$ is the conductivity of air and water corresponding to a parallel arrangement, $\mathrm{F}$ and $\alpha$ are adjustable factors.

- Bal et al. [8]

$$
\lambda=\frac{V_{i+g} \lambda_{i+g}+V_{v} \lambda_{v}}{V_{i}+V_{g}+V_{v}}
$$

where

$$
\begin{aligned}
& \lambda_{i+g}=\frac{V_{g}+V_{g}+V_{v} \lambda_{v}}{\frac{V_{i}}{\lambda_{i}}+\frac{V_{g}}{\lambda_{g}}} \\
& \lambda_{v}=\lambda_{i}=\frac{\lambda_{w} V_{i w}+\lambda_{a} V_{v a}}{V_{v w}+V_{v a}} \\
& \lambda_{g}=\frac{\lambda_{s} V_{s}+\lambda_{w} V_{g w}+\lambda_{a} V_{g a}}{V_{s}+V_{g w}+V_{g a}} \\
& V=\frac{(1+X)(1+Y)}{\rho_{s}(X, Y)} \\
& V_{s}=(1-\varepsilon) V \\
& V_{g v}=\frac{\varepsilon_{g} V_{s}}{1-\varepsilon_{g}} \\
& V_{w}=\frac{X(1+Y)}{\rho_{w}} \\
& V_{v a}=\frac{\varepsilon V-V_{g}-\left(V_{w}-V_{g w}\right)}{1+\alpha}
\end{aligned}
$$

The modelled thermal conductivity $\lambda$ can be calculated if the porosity $\varepsilon Y$ and the densities $\rho_{s}, \rho_{w}$ have been previously measured. Moreover the unknown parameters $\lambda_{s}, \varepsilon_{g}$ and $\alpha$ of the model must be identified.

With this model we have the fine comprehension of the 
elementary mechanisms. However, its use is not always suitable, in particular in the case of an application with for goal the taking into account of thermal conductivity in the energy saving in the building in unfavourable period. Moreover, to consider porosity as a parameter supposes that the material does not undergo shrinkage during decreasing of its water content.

\subsection{Proposed Models}

The most physical models suggested in the literature were not explicitly a function of the water content. To elaborate on the proposed models, we considered that the material was constituted of a solid structure with density $\rho_{d}$ and volume $V_{d}$, pores of which are occupied by water liquid with density $\rho_{w}$ and volume $V_{w}$ then humid air with density $\rho_{a}$ and volume $V_{a}$.

Furthermore, by considering $m$ as the hygroscopic material mass at a given time, $m_{w}$ its water liquid mass, $m_{v}$ its water vapour mass, $m_{a}$ its humid air mass, $m_{a s}$ its drying air mass and $m_{d}$ its solid structure mass, it can be written that:

$$
\begin{aligned}
m_{a} & =m_{v}+m_{a s} \\
V_{a} & =V_{v}+V_{a s} \\
\rho & =\frac{m_{d}+m_{w}+m_{a}}{V_{d}+V_{w}+V_{a}} \\
\rho_{a} & =\frac{m_{v}+m_{a s}}{V_{v}+V_{a s}} \\
\rho_{w} & =\frac{m_{w}}{V_{w}} \\
\rho_{d} & =\frac{m_{d}}{V_{d}} \\
x & =\frac{m_{a}}{m_{w}+m_{a}} \\
\alpha & =\frac{m_{a}}{m_{d}} \\
\beta & =\frac{\rho_{w}}{\rho_{d}} \\
\gamma & =\frac{\rho_{a}}{\rho_{d}}
\end{aligned}
$$

$\rho_{a}, \rho_{w}, \rho_{d}$ : densities of humid air, liquid water and solid material respectively;

$x$ : mass fraction of the humid air in the fluid phase.

\subsubsection{Complete Model}

We supposed water liquid, in a series arrangement with humid air, was in parallel with the solid structure. Thus, by considering the equivalent represented in figure 1 , the equivalent thermal resistance $\mathrm{R}$ of the material is:

$$
\frac{1}{R}=\frac{1}{R_{d}}+\frac{1}{R_{w, a}}
$$

where

$$
\frac{1}{R_{w, a}}=\frac{1}{R_{w}+R_{a}}
$$

$$
\begin{gathered}
R=\frac{e}{\lambda S} \\
R_{d}=\frac{e_{d}}{\lambda_{d} S_{d}} \\
R_{w}=\frac{e_{w}}{\lambda_{w} S_{w}} \\
R_{a}=\frac{e_{a}}{\lambda_{a} S_{a}} \\
S=S_{s}+S_{w} \\
S_{w}=S_{a} \\
e=e_{d}=e_{w, a}=e_{w}+e_{a}
\end{gathered}
$$

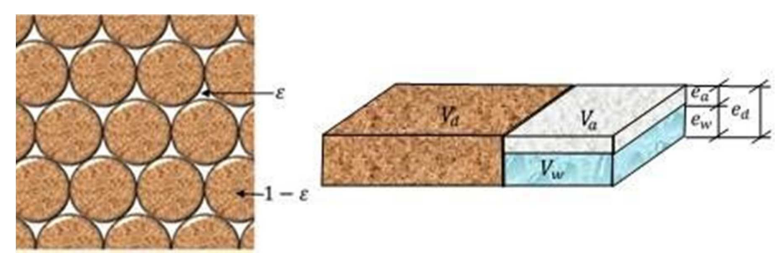

Figure 1. Model of the elementary volume of the material.

Using relations (19) to (21), the equivalent thermal conductivity of the material is:

$$
\begin{gathered}
\lambda=\varepsilon_{d} \lambda_{d}+\varepsilon \lambda_{w, a} \\
\varepsilon_{d}=\frac{V_{d}}{V}=1-\varepsilon \\
\lambda=\varepsilon_{d} \lambda_{d}+\varepsilon \lambda_{w, a}=\lambda=\lambda_{d}+\varepsilon\left(\lambda_{w, a}-\lambda_{d}\right)
\end{gathered}
$$

In other respects, water liquid was in a series arrangement with humid air so that:

$$
\begin{aligned}
\varepsilon_{w}^{\prime} & =\frac{V_{w}}{V_{w}+V_{a}} \\
\varepsilon_{a}^{\prime} & =\frac{V_{a}}{V_{w}+V_{a}} \\
\lambda_{w, a} & =\left(\frac{\varepsilon_{w}^{\prime}}{\lambda_{w}}+\frac{\varepsilon_{a}^{\prime}}{\lambda_{a}}\right)^{-1}
\end{aligned}
$$

Finally, thermal conductivity of material can be obtained using these two equations:

$$
\begin{gathered}
\varepsilon=\frac{\alpha \beta+\gamma X}{\alpha \beta+\beta \gamma+\gamma X} \\
\rho=\rho_{d} \frac{\beta \gamma(1+X+\alpha)}{\alpha \beta+\beta \gamma+\gamma X} \\
\lambda_{w, a}=\left\{\frac{1}{\rho_{a}+x\left(\rho_{w}-\rho_{a}\right)}\left[\frac{\rho_{a(1-x)}}{\lambda_{w}}+\frac{\rho_{w} x}{\lambda_{a}}\right]\right\}^{-1}
\end{gathered}
$$

For this complete model, the unknown parameters that must be identified are thus: $\lambda_{d}, \lambda_{a}, \alpha, \beta$ and $\gamma$. Out of four parameters to be identified, the model presents two variables $X$ and $x$ to determine from the independent experiments. This leads us to elaborate a simplified model by using some assumptions.

\subsubsection{Simplified Model}

We assumed that vaporization front view was at the border 
of material. Therefore, we have an ideal shrinkage of the material during the evacuation of water. Thus, the pores were only occupied by liquid water and in this case:

$$
\begin{aligned}
& x=0 \\
& \alpha=0 \\
& \varepsilon=\frac{X}{\beta+X} \\
& \rho=\rho_{d} \frac{\rho_{w}(1+X)}{\rho_{w}+\rho_{d} X}
\end{aligned}
$$

Finally, only water liquid was in parallel with the solid structure. We obtained so:

$$
\lambda_{\text {mod }}=\lambda_{d}+\frac{X}{\beta+X}\left(\lambda_{w}-\lambda_{d}\right)
$$

For this simplified model, the unknown parameters that must be identified are thus $\lambda_{d}$ and $\beta$.

The parameters are estimated by minimizing the sum $S$ of the quadratic errors between the experimental thermal conductivity $\lambda$ and the values calculated with equation (29):

$$
S=\sum_{i=1}^{n}\left(1-\frac{\lambda_{m o d}}{\lambda}\right)_{i}^{2}
$$

where $\mathrm{n}$ is the number of measurements for contents.

$$
R^{2}=1-\frac{\sum_{i=1}^{n}\left(\lambda_{i}-\lambda_{\text {mod }_{i}}\right)^{2}}{\sum_{i=1}^{n}\left(\lambda_{i}-\bar{\lambda}\right)^{2}}
$$

Fit and prediction quality were analysed by the regression coefficient $\left(R^{2}\right)$, the mean relative deviation $(M R D)$ and the standard error $(S E)$, calculated as follow:

$$
\operatorname{MRD}(\%)=\frac{100}{n} \sum_{i=1}^{n}\left|1-\frac{\lambda_{\bmod _{i}}}{\lambda_{i}}\right|
$$

with $\bar{\lambda}=\frac{\sum_{i=1}^{n} \lambda_{i}}{n} ; n$ being the number of experiments.

\subsection{Sensitivity of Simplified Model Parameters}

The sensitivity of the simplified model parameters $\lambda_{d}$ and $\beta$ is deduced from relations (34) and (35) respectively.

$$
S E=\sqrt{\frac{\sum_{i=1}^{n}\left(\lambda_{i}-\lambda_{\bmod _{i}}\right)^{2}}{n}}
$$

$$
\begin{aligned}
\frac{k}{100} \lambda_{d} \frac{\partial \lambda}{\partial \lambda_{d}} & =\frac{k}{100} \lambda_{d} \frac{\beta}{\beta+X} \\
\frac{k}{100} \beta \frac{\partial \lambda}{\partial \beta} & =\frac{k}{100} \beta \frac{\lambda_{d}-\lambda_{w}}{(\beta+X)^{2}}
\end{aligned}
$$

These two formulas represent the variation of the estimated value of $\lambda$ induced by a relative variation of $k \%$ of respectively the parameters $\lambda_{d}$ and $\beta$ from their nominal values.

\section{Results and Discussion}

\subsection{Experimental Results}

The validation of the elaborate model was based on three types of materials: an isotropic homogeneous material (compressed soil building blocks), an isotropic composite material (laterite based bricks with $0.0611 \mathrm{~kg}_{\mathrm{mi}} \cdot \mathrm{kg}_{\mathrm{la}}{ }^{-1}$ millet waste) and an orthotropic homogeneous material (wood of oak). The experimental values of the thermal conductivity $\lambda$ are obtained by Talla [16] for compressed soil building blocks, Bal et al. [8] for laterite based bricks with 0.0611 $\mathrm{kg}_{\mathrm{mi}} \cdot \mathrm{kg}_{\mathrm{la}}{ }^{-1}$ millet waste and Nadeau and Puiggali [17] for wood of oak the thermal. Figure 2 represents the experimental values of the thermal conductivity obtained for these three materials for different values of the water content (between 0 and $0.139 \mathrm{~kg}_{\mathrm{w}} \cdot \mathrm{kg}_{\mathrm{db}}{ }^{-1}, 0$ and $0.054 \mathrm{~kg}_{\mathrm{w}} \cdot \mathrm{kg}_{\mathrm{db}}{ }^{-1}$, 0.025 and $1.068 \mathrm{~kg}_{\mathrm{w}} \cdot \mathrm{kg}_{\mathrm{db}}{ }^{-1}$ respectively).

\subsection{Validation of Proposed Model}

The parameters $\lambda_{d}$ and $\beta$ of proposal model were determinate, for these three materials, by minimization of the sum of the quadratic differences (equation (30)) between the theoretical value of thermal conductivity $\lambda_{\bmod }$ calculated using equation (29) and the experimental values $\lambda$. Table 1 shows the parameters of this model fitted to the experimental thermal conductivities data of materials tested. In the same table, we have the values of the regression coefficient $\left(R^{2}\right)$, the mean relative deviation $(M R D)$ and the standard error $(S E)$ resulting from equations (31) to (33).

Table 1. Estimated parameters of the new model for the thermal conductivity of compressed soil building blocks and comparison with experimental data.

\begin{tabular}{llll}
\hline Parameters & CSBB $^{(2)}$ & LBB $^{(3)}$ with $\mathbf{0 . 0 6 1 1} \mathbf{~ k g}_{\mathrm{mi}} \cdot \mathbf{k g}_{\mathrm{la}}{ }^{-1}$ millet waste additive & Wood of oak \\
\hline$\lambda_{w}\left(\mathrm{Wm}^{-1} \mathrm{~K}^{-1}\right)$ & 0.612 & 0.612 & 0.612 \\
$\lambda_{w}\left(\mathrm{Wm}^{-1} \mathrm{~K}^{-1}\right)$ & 1.016 & 0.674 & 0.135 \\
$\beta$ & 0.973 & 0.670 & 1.474 \\
MRD $(\%)$ & 1.01 & 3.61 & 4.78 \\
$R^{2}$ & 0.998 & 0.985 & 0.979 \\
$\mathrm{SE}\left(\mathrm{Wm}^{-1} \mathrm{~K}^{-1}\right)$ & 0.021 & 0.037 & 0.017 \\
\hline
\end{tabular}

${ }^{(2)} \mathrm{CSBB}$ : Compressed soil building blocks

${ }^{(3)}$ LBB: Laterite based bricks 


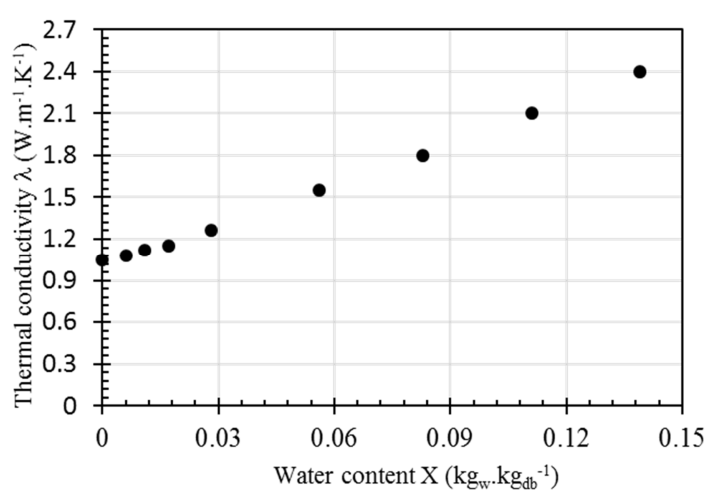

(a) Compressed soil building blocks, Talla [16]

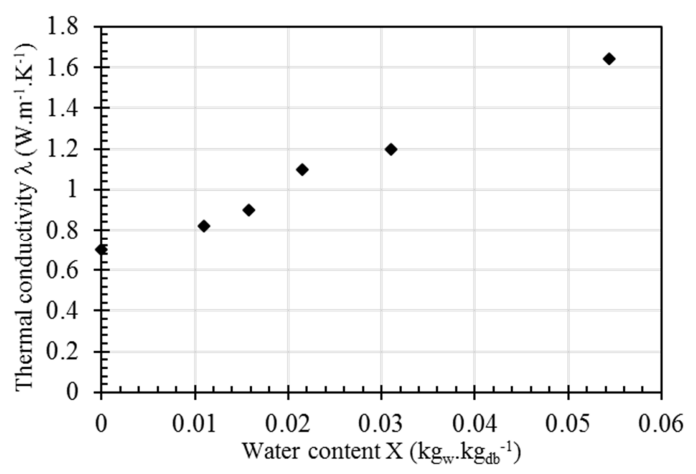

(b) Laterite based bricks with $0.0611 \mathrm{~kg}_{\mathrm{mi}} \cdot \mathrm{kg}_{\mathrm{la}}{ }^{-1}$ waste additive, Bal et al. [8]

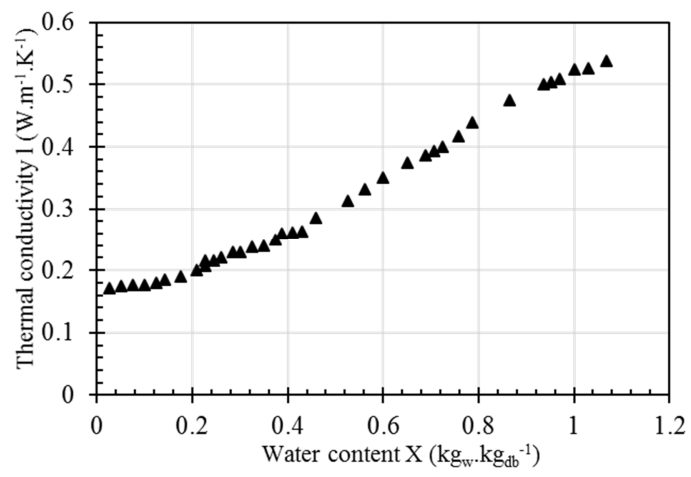

(c) wood of oak, Nadeau and Puiggali [17]

Figure 2. Experimental results of thermal conductivity for different materials.

\subsection{Discussion}

The mean relative deviation between the experimental values and the theoretical values calculated with relation (32) was $1.01 \%, 3.61 \%$ and $4.78 \%$ respectively for compressed soil building blocks, laterite based bricks with 0.0611 $\mathrm{kg}_{\mathrm{mi}} \cdot \mathrm{kg}_{\mathrm{la}}{ }^{-1}$ millet waste and wood of oak. Moreover, the regression coefficient $\left(R^{2}\right)$ is $0.998,0.985$ and 0.979 in the order of materials tested. The results obtained, by using the elaborate model, are very satisfying for the two isotropic materials (compressed soil building blocks and laterite based bricks with $0.0611 \mathrm{~kg}_{\mathrm{mi}} \cdot \mathrm{kg}_{\mathrm{la}}{ }^{-1}$ millet waste) but less for orthotropic material (wood of oak). All the experimental and theoretical values are represented on figure 3 .

The different models described by equations (4) to (13) were tested by Bal et al. [8] for laterite based bricks with $0.0611 \mathrm{~kg}_{\mathrm{mi}} \cdot \mathrm{kg}_{\mathrm{la}}{ }^{-1}$ millet waste additive. Table 2 gives the values of the estimated parameters of each model both with the mean deviation between the experimental and the modelled values of the thermal conductivity according to these authors. The results show that, considering the classical models described by equations (4) to (12), only the Woodside and Messmer's model and the Krischer's model lead to a satisfying representation of the variation of the thermal conductivity as a function of the water content. Nevertheless, the estimated values of the thermal conductivity of the solid fraction $\lambda_{d}$ are greater than $100 \mathrm{Wm}^{-1} \mathrm{~K}^{-1}$. These values have not any physical meaning.

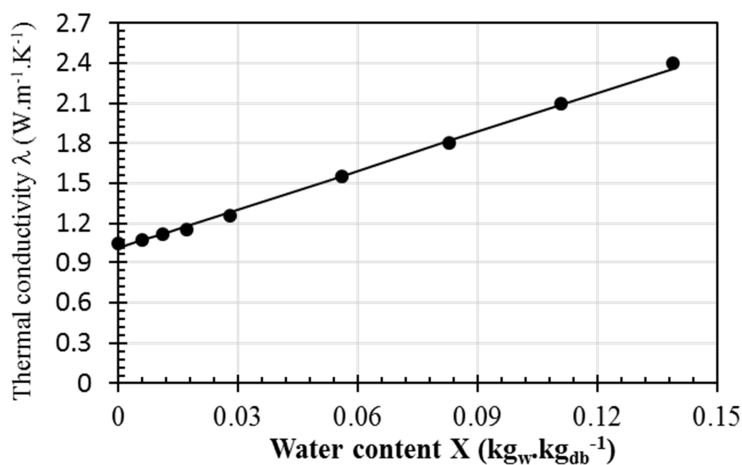

- Estimated values Calculated values

(a) Compressed soil building blocks, experimental values from Talla [16]

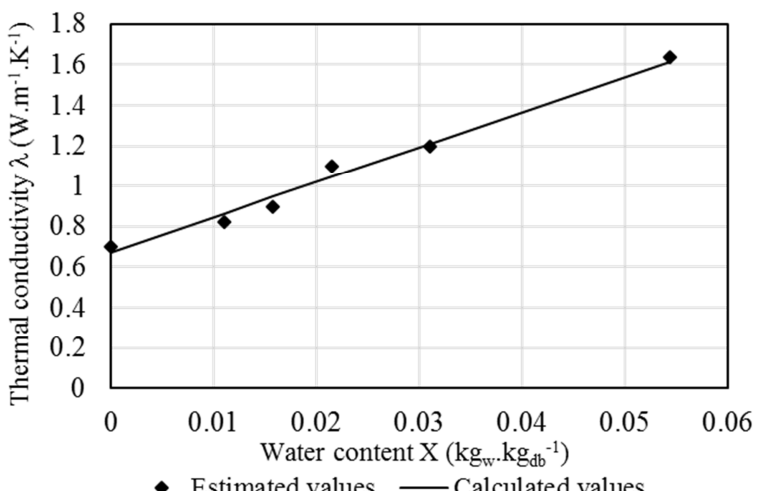

- Estimated values Calculated values

(b) Laterite based bricks with $0.0611 \mathrm{~kg}_{\mathrm{mi}} \cdot \mathrm{kg}_{\mathrm{la}}{ }^{-1}$ millet waste additive, experimental values from Bal et al. [8]

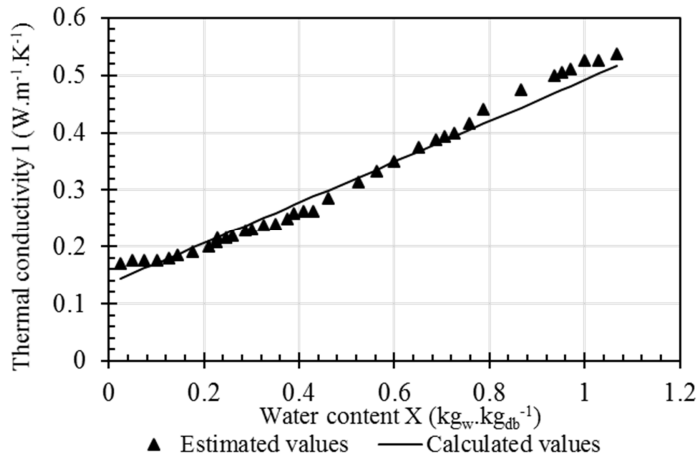

(c) wood of oak, experimental values from Nadeau and Puiggali [17]

Figure 3. Experimental results and calculated of thermal conductivity for different materials. 
Table 2. Estimated parameters of the models and mean relative deviation between experimental and modelled thermal conductivities for laterite based bricks with $0.0611 \mathrm{~kg}_{\mathrm{mi}} \mathrm{kg}_{\mathrm{la}}^{-1}$ millet waste additive, Bal et al. [8]

\begin{tabular}{|c|c|c|c|c|c|c|}
\hline Model & $\lambda_{d}\left(\mathrm{Wm}^{-1} \mathrm{~K}^{-1}\right)$ & $\alpha$ & $\mathbf{F}$ & $\varepsilon$ & $\varepsilon_{g}$ & MRD (\%) \\
\hline Parallel & 1.63 & - & - & - & - & 21.7 \\
\hline Series & $8.6 \times 10^{7}$ & - & - & - & - & 91.4 \\
\hline $\mathrm{HS}_{\min }$ & 0.79 & - & - & - & - & 88.7 \\
\hline $\mathrm{HS}_{\max }$ & 1.90 & - & - & - & - & 20.5 \\
\hline Beck & 21.7 & - & - & - & - & 16.2 \\
\hline Woodside & $3.0 \times 10^{19}$ & 0.947 & - & - & - & 7.8 \\
\hline Krischer & 141 & 0.0868 & - & - & - & 6.7 \\
\hline Ingersoll & 1.88 & 0.034 & 1.72 & - & - & 15.5 \\
\hline Bal & 3.57 & 0.0297 & - & 0.39 & 0.0224 & 4.0 \\
\hline
\end{tabular}

Tables 1 and 2 show that the mean relative deviation of $3.6 \%$ resulting from the elaborate simplified model $(3.6 \%)$ is smaller than the deviation of $4.0 \%$ given by the model of Bal et al. [8]. Moreover, the thermal conductivity of the solid fraction $\lambda_{d}=0.674 \mathrm{Wm}^{-1} \mathrm{~K}^{-1}$ resulting of the developed model corresponds to true-to-life description; the experimental value of the solid fraction obtained by Bal et al. [8] was $\lambda_{d}=0.70 \mathrm{Wm}^{-1} \mathrm{~K}^{-1}$. The value resulting from the model of these authors $\left(\lambda_{d}=3.57 \mathrm{Wm}^{-1} \mathrm{~K}^{-1}\right)$ deviates relatively from the experimental value. The porosity taken as a constant in their model, when the material would undergo a shrinkage by losing water, could be a justification of this difference.

In other respects, the knowledge of the second parameter $\beta$ of developed model informs us about the density of the solid fraction. If $\beta<1$, case of isotropic materials examined in this article, the density of the solid fraction is higher than the density of water. In the contrary case, case of orthotropic material examined in our work, the density of the solid fraction is lower than the density of water.

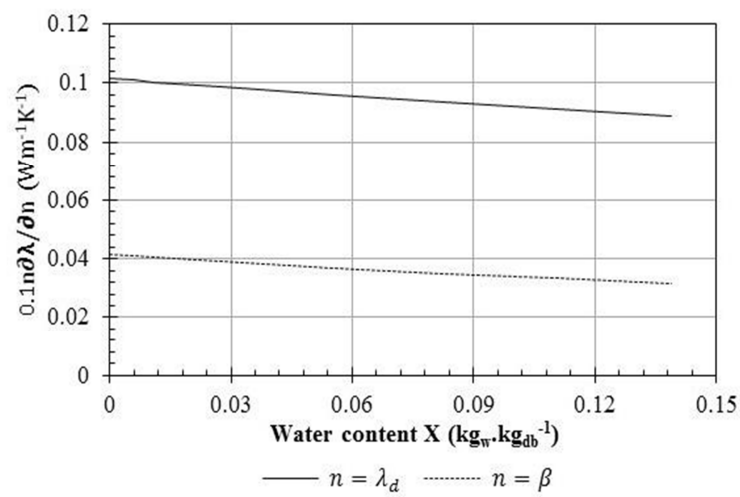

Figure 4. Residual variation of $\lambda$ induced by a relative variation of $10 \%$ of each parameter for compressed soil building blocks.

Formulas (34) and (35) represent the variation of the estimated value of $\lambda$ indices by a relative variation of $k \%$ of respectively the parameters $\lambda_{d}$ and $\beta$ from their nominal values. For example, Fig. 4 represents this sensitivity for compressed soil building blocks. It shows that the simplified model is less sensitive to parameter $\beta$ than with parameter $\lambda_{d}$ : a relative variation of $10 \%$ on the parameter $\lambda_{d}$ has an effect 2.45 times more significant than on the parameter $\beta$, on the simulated values. However, the sensitivity as of these two parameters on the simulated values of thermal conductivity is overall low: maximum 0.1 for $\lambda_{d}$ and 0.04 for $\beta$. At last, we note that the two curves of sensitivity decrease when the water content increases.

\section{Conclusion}

In this work, an adapted simplified model has been developed to predict the thermal conductivity $\lambda(X)$ of the hygroscopic materials buildings as a function of water content $X$. Three hygroscopic materials buildings were tested and the prediction capability of this simplified model was verified. Very good results were obtained in both correlation and prediction of thermal conductivity, particularly for isotropic materials. These good results validated the fundamental assumption which guided the development of the simplified model. We assumed that the material underwent an ideal shrinkage during the evacuation of water, with front view of vaporisation at the border of sample. The new model is easy to use. The suitability of this simplified model for other hygroscopic materials buildings will be further studied.

\section{Acknowledgements}

Author expresses its sincere thanks to National Advanced School of Engineering, University of Yaounde I and National Advanced School of Public Works of Yaounde, for her material support for this work.

\section{Abbreviations}

\author{
Letters \\ e thickness (m) \\ $\mathrm{m} \quad \operatorname{mass}(\mathrm{kg})$ \\ $\mathrm{V} \quad$ volume $\left(\mathrm{m}^{3}\right)$ \\ $\mathrm{X} \quad$ Dry basis water content $\left(\mathrm{kg}_{\mathrm{w}} \mathrm{kg}_{\mathrm{db}}{ }^{-1}\right)$
}

Greek letters

$\begin{array}{ll}\lambda & \text { thermal conductivity }\left(\mathrm{Wm}^{-1} \mathrm{~K}^{-1}\right) \\ \varepsilon & \text { porosity } \\ \rho & \text { density }\left(\mathrm{kgm}^{-3}\right)\end{array}$




\section{Subscripts}

$\begin{array}{ll}\mathrm{a} & \text { air } \\ \mathrm{d} & \text { solid phase } \\ \mathrm{db} & \text { dry basis } \\ \mathrm{la} & \text { laterite } \\ \mathrm{mi} & \text { millet waste } \\ \mathrm{mod} & \text { model } \\ \mathrm{w} & \text { Water phase }\end{array}$

\section{References}

[1] Raghavan VR., Martin H. Effect of moisture content on the thermal effusivity of wood cement-based composites. $J$ Phys D: Appl Phys 1998; 31:34-57.

[2] Bouguerra A, Diop MB, Laurent JP, Benmalek ML, Queneudec M. Effect of moisture content on the thermal effusivity of wood cement-based composites. J Phys D: Appl Phys 1998; 31:34-57.

[3] Adam EA, Jones PJ. Thermophysical properties of stabilised soil building blocks. Build Environ 1995; 30(2): 245-53.

[4] Meukam P, Jannot Y, Noumowe A, Kofane TC. Thermo physical characteristics of economical building materials. Constr Build Mater 2004; 18(6): 437-43.

[5] Khedari J, Watsanasathaporn P, Hirunlabh J. Development of fibre-based soil-cement block with low thermal conductivity. Cem Concr Compos 2005; 27(1): 111-6.

[6] Omubo-Pepple VB, Opara FE, Ogbonda C. Thermal conductivity of reinforced cement stabilized lateritic brick. $J$ Eng Appl Sci 2010; 5(2): 178-80.

[7] Goodhew S, Griffiths R. Sustainable earth walls to meet the building regulations. Energy Build 2005; 37(5): 451-9.
[8] Bal H, Jannot Y, Gaye S, Demeurie F. Measurement and modelisation of the thermal conductivity of a wet composite porous medium: Laterite based bricks with millet waste additive. Constr Build Mater 2013; 41: 586-593.

[9] Wiener O. Lamellare Doppelbrechung. Phys Z 1904; 5: 332 8.

[10] Hashin Z, Shtrikman S. A variational approach of the effective magnetic permeability of multiphase materials. J Appl Phys 1962; 33: 3125-31.

[11] Tong F, Jing L, Zimmerman RW. An effective thermal conductivity model of geological porous media for coupled thermo-hydro-mechanical systems with multiphase flow. Int $J$ Rock Mech Min Sci 2009; 46: 1358-69.

[12] Beck JM, Beck AE. Computing thermal conductivities of rocks from chips and convenient specimens. J Geophys Res $1965 ; 70: 7227-39$.

[13] Krischer O. Die wissenschaftlichen Grundlagendes Trockn ungstechnik. 1st ed. Heidelberg: Springer-Verlag; 1956.

[14] Woodside W, Messmer JH. Thermal conductivity of porous media. J Appl Phys 1961; 32: 1688-706.

[15] Ingersoll JG. Analytical determination of soil thermal conductivity and diffusivity. J. Sol Energy Eng 1988; 110: 306-12.

[16] Talla A. Measurement and modelling of water content effects on thermal properties of compressed soil building blocks. British Journal of Applied Science \& Technology 2015; 6(5): 520-533.

[17] Nadeau JP., Puiggali JR. Séchage - des processus physiques aux procédés industriels. Tec Doc 1995, Lavoisier. 